\author{
А.Д. Шмелев \\ Институт русского языка им. В. В. Виноградова РАН \\ (Москва, Россия) \\ shmelev.alexei@gmail.com
}

\title{
КОГДА И КАК МОЖНО ИСПРАВЛЯТЬ ОШИБКИ В ГРАММАТИЧЕСКИХ ОПИСАНИЯХ?*
}

Ошибки и противоречия в существующих грамматических описаниях разнообразны, и в зависимости от того, с каким типом ошибки мы имеем дело, можно предложить разные способы их исправления. В некоторых случаях речь идет об очевидном недосмотре авторов описания, когда исправление ошибки не связано ни с каким новым лингвистическим знанием. Такие ошибки легко могут быть исправлены; они не представляют особого интереса. С противоположной ситуацией мы имеем дело, когда неточность в грамматическом описании вызвана тем, что какие-то языковые факты не попали в поле зрения автора. Здесь ошибку можно исправить, лишь обнаружив языковой факт, ускользнувший от внимания грамматистов. В некоторых случаях мы сталкиваемся с несогласованностью разных фрагментов описания. Здесь сделать описание последовательным обычно бывает можно разными способами, но в любом случае придется отказаться от одного из противоречащих друг другу утверждений. От случаев такого рода отличаются случаи, когда описание недостаточно эксплицитно, так что при помощи специальных разъяснений можно сделать его формально верным, хотя, возможно, не оптимальным. Впрочем, важно учитывать все импликации таких разъяснений: часто они влекут за собою существенное увеличение громоздкости каких-то других фрагментов грамматического описания. Кроме того, есть еще целый ряд случаев, когда попытка посредством разъяснений сохранить имеющееся описание (которое не учитывало взаимодействия разных областей грамматики), приводит к крайней неестественности грамматических правил.

Ключевые слова: Грамматическое описание, грамматическое правило, неточность в описании, русский язык, местоимения, числительные, притяжательные прилагательные, фамилии.

* В данной статье, среди прочего, исправляются неточности и уточняются формулировки, содержащиеся в некоторых моих предшествующих публикациях. Окончательный вариант статьи написан при поддержке Российского фонда фундаментальных исследований (проект № 18-01200650 «Семантические категории в грамматическом строе русского языка»). 
Как известно, грамматические описания одного и того же языка и даже одного и того же языкового явления бывают весьма разнообразны, и многое в них зависит от теоретических установок их авторов. Однако, независимо от того, насколько мы согласны с общими установками, положенными в основу грамматического описания, мы можем с полным доверием опираться на его результаты, только если убедимся, что это описание не содержит логических противоречий и соответствует языковым фактам.

Ошибки и противоречия в существующих грамматических описаниях тоже довольно разнообразны, и в зависимости от того, с каким типом ошибки мы имеем дело, можно предложить разные способы их исправления.

В некоторых случаях речь идет об очевидном недосмотре авторов описания, когда исправление ошибки не связано ни с каким новым лингвистическим знанием (как, напр., утверждение «Грамматики-1970», будто у существительных с основой на [г], [к], [х] формы именительного падежа множественного числа всегда образуются от основ на мягкие согласные [г'], [к’], [х’]). Говорилось буквально следующее: «Существительные 1-го субстантивного склонения, основы которых оканчиваются на твердые [г], [к], [х, помимо названных форм, образуют от основы на мягкие [г’], [к'], [х'] также и формы именит. (винит.) пад. мн. ч.; например: пироги, окошки, мухи» [Плотникова 1970: 386]. Ясно, что автор этого описания просто забыл о таких формах, как рога, окорока, меха, где никакого смягчения основы не происходит. Нелепо было бы на основании этого описания говорить, что «Грамматика-1970» предписывает употреблять формы «рогя», «окорокя», «мехя» со смягчением основы (и считает именно эти формы «правильными»). Такие ошибки легко могут быть исправлены; они не представляют особого интереса.

С противоположной ситуацией мы имеем дело, когда неточность в грамматическом описании вызвана тем, что какие-то языковые факты не попали в поле зрения автора. В таких случаях ошибку можно исправить, лишь обнаружив языковой факт, ускользнувший от внимания грамматистов. При этом чрезвычайно важно быть предельно внимательными к описываемым языковым фактам, иначе, исправляя действительные или мнимые обнаруженные ошибки, можно легко сделать новые ошибки. Проиллюстрируем сказанное на ряде примеров.

В «Грамматике-1953» говорится (автор соответствующего раздела - А. Б. Шапиро), что местоимения «несколько, сколько и столько обнаруживают полную аналогию с числительными». При этом отмечается: «Неопределенно-количественные числительные, за исключением несколько, могут сочетаться не только с названиями предметов, поддающихся счету, но и с существительными вещественными и отвлеченными, напр.: сколько муки, сколько сахару, сколько радости...» По этому поводу мы написали (в сборнике в честь П. Гарда), что в «Грамматике-1953» не учитывается «тот факт, что подобные сочетания возможны только в именительном и винительном падеже» [Булыгина, Шмелев 1992: 432], Там же мы обратили внимание на формулировку П. Гарда: « Les numéraux non chiffrés peuvent aussi avoir complément au génitif singulier, s'il s'agit de choses qui ne se comptent pas... Mais les syntagmesde ce genre ne peuvent s'employer qu'au nominatif et à l'accusatif » [Garde 
1980 : 241]. В связи с ней мы написали, что П. Гард «делает общее утверждение о способности неопределенно-количественных существительных в именительном и винительном падеже сочетаться с обозначениями неисчисляемых существительных (в родительном падеже единственного числа), никак не различая сколько и столько, способные к такому употреблению, и несколько, сочетающееся только с обозначениями дискретных множеств» [Булыгина, Шмелев 1992: 432]. Однако, как будет видно из дальнейшего: сочетания слов сколько и столько с вещественными и отвлеченными существительными возможны не только в именительном и винительном падеже, но и в других косвенных падежах.

Здесь уместно заметить, что до самого последнего времени грамматики игнорировали формы ед. ч. слов столько и сколько ${ }^{1}$. Так, во вступительной статье к первому изданию «Грамматического словаря русского языка» А. А. Зализняка парадигма словоизменения этих слов была описана следующим образом: «Числительные ско́лько, не́сколько, сто́лько, мно́го, немно́го склоняются по следующему единому образцу: И. ско́лько, Р., П. ско́льких, Д. ско́льким, Т. ско́лькими, В. неод. ско́лько (ср.: ско́лько корабле́й вь́́ ви́дите?), В. одуш. ско́льких \| ско́лько (т.е. возможно, например: ско́льких госте́й вьі́ пригласи́ли? и ско́лько госте́й вьі́ пригласи́ли?)» [Зализняк 1977]. Словарные статьи указанных числительных в «Грамматическом словаре» соответствовали приведенному описанию, а прочие описания русского словоизменения давали ту же картину, только в большинстве случаев менее эксплицитно и корректно.

Однако несложный мысленный эксперимент показывает, что столько изменяется по числам и в единственном числе имеет полный набор падежных форм (столького не хватает; столькому научился; я ему стольким обязан; о стольком надо поговорить и т.д.). Соответствующие формы нередко встречаются в текстах на русском языке.

Эта лакуна в грамматических описаниях русского языка была отмечена в нашей статье [Булыгина, Шмелев 2000], а незадолго до ее публикации я рассказал об этом А. А. Зализняку. В настоящее время ситуация отчасти изменилась к лучшему: в новое издание «Грамматического словаря» [Зализняк 2003] была внесена уточненная информация относительно парадигм словоизменения слова столько. К общему описанию склонения числительных ско́лько, не́сколько, сто́лько, мно́го, немно́го во вступительной статье к словарю было добавлено замечание: «Отметим, что сто́лько может выступать также как местоимение со значением «столь многое» и тогда склоняется с окончаниями единственного числа: я́ сто́льким Вам обя́зан, о сто́льком переговори́ли и т п.» [Зализняк 2003: 68]; соответственно модифицирована и словарная статья в словаре.

До сих пор большинство грамматических справочников (в том числе лучших, напр. [Еськова 2015]), по-прежнему не учитывает возможности склонения

${ }^{1}$ В нескольких последующих абзацах кратко пересказываются и одновременно уточняются некоторые положения моей статьи в электронном сборнике, посвященном 80-летию А. А. Зализняка. 
с окончаниями единственного числа для слова столько. Но и в «Грамматическом словаре» уточнение не было доведено до конца: в нем (в частности, и в издании [Зализняк 2008]) пока недостает информации о возможности употреблять с окончаниями единственного числа не только слово столько, но и слово сколько.

Между тем такой же мысленный эксперимент показывает, что возможностью употребляться с окончаниями единственного числа обладает и местоимение сколько в «восклицательном» значении (Скольким я ему обязан! и т.д.), и, кстати, соответствующие формы также нередко встречаются в текстах (напр., А сколького я еще не рассказала! [Марина Цветаева]). В то же время необходимо подчеркнуть, что для неопределенного местоимения несколько склонение с окончаниями единственного числа невозможно, поэтому в «уточнении» важно не зайти слишком далеко, не попасть в плен аналогии и не приписать способность изменяться по числам слову несколько.

Можно заметить также, что из описания слова столько в словаре [Зализняк 2003; 2008] может создаться впечатление, что в присубстантивном употреблении оно склоняется с окончаниями множественного числа, а в абсолютивном употреблении (без указания предмета) - с окончаниями единственного числа. Это не совсем так.

Во-первых, в абсолютивном употреблении возможно не только единственное, но и множественное число, и поэтому неточны указания, которые даются в словаре в отношении обоих слов: «косв. формы употребляются только с названиями предметов...». Соответствующий пример приводился еще в словаре В.И. Даля: Стольких перехватали, что беда! - и давалось пояснение: «столько людей». При этом семантическое различие между абсолютивными употреблениями единственного и множественного числа вполне прозрачно и системно, оно полностью аналогично различию между абсолютивными всё и все или многое и многие. Единица с характеристиками единственного числа представляет собою обобщенное обозначение «вещей» или явлений, тогда как единица с характеристиками множественного числа, указывает на людей [Булыгина, Шмелев 2000: 293].

Во-вторых, слова столько и сколько могут склоняться с окончаниями единственного числа не только в абсолютивном, но и в присубстантивном употреблении. Случаи такого рода относительно немногочисленны, но и не являются чем-то исключительным (впрочем, как кажется, ограничиваются средним и - реже мужским родом $)^{2}$ :

- . . . этой-то женщине, так величаво сидящей на ее диване, окруженной стольким богатством, такою изящною роскошью, говорят, что ее побьют. [Надежда Дурова]

• . ..зачем оставить это дело, стольким трудом приобретенное?.. [Николай Гоголь]

- Сколько можешь сделать добра. Сколькому злу помешать... [Константин Станюкович]

2 Часть примеров извлечена из «Национального корпуса русского языка» (НКРЯ). Они приводятся в том виде, в каком содержатся в Корпусе. 
- Ни один край прежней царской России (...) не был облеплен стольким количеством глупейших резолюций и высказываний, как заполярный Мурман. [Константин Паустовский]

- $\quad$ после столького пережитого [Евгений Евтушенко]

- Ты, стольким покаяньем, раскаяньем и мукой искупивший свои грехи! [Владлен Давыдов (2004)]

Таким образом, мы видим, что мнимое «упущение» А. Б. Шапиро в «Грамматике-1953» на поверку оказывается лишь недостаточно эксплицитным описанием соответствующего фрагмента языковой системы, тогда как описание П. Гарда отклоняется от языковых фактов в том отношении, что сочетания слов сколько и столько с вещественными и отвлеченными существительными возможны не только в именительном и винительном падеже, но и в других косвенных падежах. С другой стороны, когда мы писали, что из неопределенно-количественных числительных в именительном и винительном падеже только сколько и столько способны сочетаться с обозначениями неисчисляемых существительных, в то время как несколько в норме сочетается только с обозначениями дискретных множеств, мы тоже были не совсем правы. Употребление слова несколько в единственном числе все же возможно (в основном в сочетании с существительным время). Примеры, когда несколько стоит в именительном или винительном падеже, встречаются не так уж редко (легко обнаруживаются тысячи примеров), напр.:

- Через несколько времени он вернулся в Москву... [Владислав Ходасевич]

- Прошло несколько времени... [Василий Гроссман]

- Несколько времени она всматривалась во что-то вдали. [Борис Хазанов]

Примеры с творительным и предложным падежами намного более редки; хотя они тоже обнаруживаются, но находятся на грани современной нормы: располагал нескольким временем, нескольким временем позже. Примеры с дательным и предложным падежами, как и примеры с другими существительными практически не встречаются.

Встает вопрос, как отразить эти факты в грамматическом описании. Самое простое решение могло бы состоять в том, чтобы приписать местоимениям столько и сколько (но не несколько!) в присубстантивном употреблении способность изменяться по числам. Что касается до абсолютивного употребления, формальное числовое различие соответствует содержательному противопоставлению «вещей» и людей; не так уж важно, считать ли это различие словоизменительным или классифицирующим. Что же касается до слова несколько, то можно было бы указать, что оно способно сочетаться не только с существительными во множественном числе, но и с существительным время, но только в именительном и винительном падежах (разумеется слово время при этом стоит в родительном падеже, или, если угодно, в счетной форме), тогда как чрезвычайно редкие и, возможно, ненормативные примеры сочетания нескольким временем целесообразно игнорировать.

Можно добавить, что есть и другие формы от рассматриваемых основ, употребительные в современном языке, но также не предусмотренные словарями 
и грамматическими справочниками. Слово сколько в сочетании с предлогом в современной разговорной речи активно используется в значении 'который час' (заметим, что аналогичного значения нет у слов столько и несколько). Первоначально использовались конструкции со словом час, как в следующих примерах из романа «Что делать?» Николая Чернышевского:

- $\quad$ Во сколько часов вы будете у нее?

- Это значит, ты во сколько же часов уснула?

Ср. также:

- $\quad$ Во сколько же вы часов трапезуете, отче? [В. И. Немирович-Данченко. Святые горы (1880)]

Однако эти конструкции издавна встречались и без слова час, напр.:

- $\quad$ Если хотите, приходите, и мы почитаем вместе. - Во сколько? [Иван Бунин]

- $\quad$ Во сколько едешь? - В десять тридцать. [Серафимович А.С. (Попов А.С.). Что я видел (1929-1930)]

- Капитан взглянул на часы: - Во сколько у нас встреча с Солнечкой, помнишь? [Сергей Розанов. Приключения Травки (1938)]

- Во сколько у нас стрельба? - В 6:30. [Л. К. Бронтман. Дневники и письма (1932-1942)]

- Во сколько встаешь? - Обычно в 2-3. [Л. К. Бронтман. Дневники и письма (1932-1942)]

- $\quad$. .во сколько мы пойдем на стрельбище? [Тихий Дон]

- Скажите, пожалуйста, во сколько завтра начнут пускать посетителей? [Владимир Дудинцев]

- Мама встает в семь часов и тратит на одевание десять минут. Зато папа чистит зубы пять минут. Бабушка ходит в магазин столько, сколько мама одевается плюс папа чистит зубы. А дедушка читает газеты, сколько бабушка ходит в магазин минус во сколько встает мама. [Виктор Драгунский]

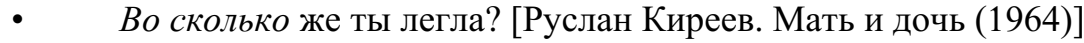

- Так во сколько вас завтра разбудить по телефону? [Юрий Домбровский]

По-видимому, эти формы следует считать принадлежащими не просторечию, а разговорной речи. С грамматической точки зрения существенно, что при склонении слова сколько в рассматриваемом значении ударение переходит на окончание (со скольки́х и до скольки́x). Вообще говоря, ударение на окончании в формах слова сколько считается просторечным; в новейшем «Орфоэпическом словаре» [Еськова 2015] оно характеризуется как «неправильное», что является более решительным запретом, нежели просто «не рекомендуемое». Однако произношение формы скольких в рассматриваемом значении с ударением на основе было бы неестественно и воспринималось бы как речь иностранца, не вполне овладевшего закономерностями русской разговорной речи. Поэтому для данного значения следует считать 
нормативным именно ударение на окончании. Кроме того, в устной речи широко используются формы со скольки́ и до скольки́, как правило, также игнорируемые нормативными словарями; правда, здесь есть основания пока еще считать использование этих форм не вполне отвечающим литературной норме.

Приведу еще один пример неточности в формулировке грамматического правила, связанной с тем, что не были учтены некоторые языковые факты. В статье о русских «притяжательных прилагательных» мы писали: «словосочетание слова nanbl неоднозначно: оно может пониматься - в соответствии с двумя значениями слова nana - как 'слова отца' или как 'слова папы римского'. Но сочетание nanины слова однозначно понимается как 'слова отца'» [Копчевская, Шмелев 1994: 218-219]. Мы связывали это с требованием «фамильярности»: посессивы рассматриваемого типа могут быть образованы только от неформальных номинаций лица, а поскольку папа (Римский) к неформальным номинациям не относится, посессив на -ин от него не может быть образован. (Эта формулировка с незначительными изменениями была повторена мною и в более поздней статье [Шмелев 2008: 930].)

Сейчас мне кажется удивительным, что в момент написания цитированной статьи мы не вспомнили хорошо известное нам стихотворение Алексея Толстого «Бунт в Ватикане», в котором в первой же строфе говорится:

- Взбунтовалися кастраты,

Входят в папины палаты...

Посессив папины образован как раз от существительного папа (Римский). Тем самым становится очевидным, что наша формулировка должна была бы быть менее категоричной. (Впрочем, следует иметь в виду, что шутливое стихотворение Алексея Толстого может предполагать фамильярное отношение к папе Pимскому.)

С иной ситуацией мы сталкиваемся, когда имеем дело с несогласованностью разных фрагментов описания, напр. когда одновременно утверждается, что наречия не имеют форм словоизменения и что наречия на -о имеют сравнительную степень в качестве формы словоизменения. Факты прекрасно известны авторам такого описания, но очевидно, что они не позаботились о том, чтобы оно было непротиворечивым. Здесь сделать описание последовательным обычно бывает можно разными способами, но в любом случае придется отказаться от одного из противоречащих друг другу утверждений.

От случаев такого рода отличаются случаи, когда описание недостаточно эксплицитно, так что при помощи специальных разъяснений можно сделать его формально верным, хотя, возможно, не оптимальным. Так, обычно считается, что род для имен существительных - словоклассифицирующая категория и что фамилии относятся к существительным. Этому явно противоречит представление, согласно которому при заключении брака можно «взять фамилию мужа» и фамилия берется в особой, женской форме, не совпадающей с мужской, и при этом женская форма не считается «другой» фамилией. Формальный выход из этого противоречия мог бы состоять в том, чтобы выделить фамилии в особый подкласс существительных, для которого происходит изменение по родам (но при этом категория рода имеет 
лишь два значения: мужской и женский род: средний род для фамилий невозможен). В этот же класс, вероятно, можно включить существительные, образованные путем субстантивации прилагательных (такие, как больной, вожатый, русский). Другое решение могло бы состоять в том, чтобы объявить мужские и женские фамилии разными словами, связанными словообразовательными отношениями (напр. словообразованием «по конверсии»).

Впрочем, важно учитывать все импликации таких разъяснений: часто они влекут за собою существенное увеличение громоздкости каких-то других фрагментов грамматического описания. Это касается, в частности, ряда случаев супплетивизма (выбор между словоформами лет и годов в качестве формы род. мн. слова год, распределение основ люд- и человек- в качестве основ форм мн. числа слова человек и др.; подробнее см. [Шмелев 2012]). Кроме того, есть еще целый ряд случаев, когда попытка посредством разъяснений сохранить имеющееся описание (которое не учитывало взаимодействия разных областей грамматики), приводит к крайней неестественности грамматических правил.

\section{Литература}

Бульгина Т.В., Шмелев А. Д. Механизмы квантификации в естественном языке и семантика количественной оценки // Референция и проблемы текстообразования. М.: Наука, 1988. С. 5-18.

Бульгина Т.В., Шмелев А.Д. Семантические и морфологические особенности местоимений: структура парадигм // Linguistique et slavistique. Mélanges offerts à Paul Garde. Paris: Université de Provence ; Institut d'études slaves, 1992. T. 1. P. 425436.

Бульгина T.B., Шмелев А.Д. Числительные в русском языке; лексикографические лакуны // Слово в тексте и в словаре. М.: Языки русской культуры, 2000. C. 289-306.

Еськова Н. А., Борунова С. И., Воронцуова В. Л. Орфоэпический словарь русского языка. М.: АCT, 2015. 1008 c.

Зализняк А. А. Грамматический словарь русского языка. Словоизменение. М.: Русский язык, 1977. 880 с.

Зализняк А. А. Грамматический словарь русского языка. Словоизменение. М.: Русские словари, 2003. 800 с.

Зализняк А. А. Грамматический словарь русского языка. Словоизменение. М.: АСТ-ПРЕСС КНИГА, 2008. 800 с.

Копчевская-Тамм М., Шмелев А. Алешина с Машей статья (о некоторых свойствах русских «притяжательных прилагательных») // Scando-Slavica, 1994, Т. 40. P. 209-228.

Плотникова В. А. Склонение имен // Грамматика современного русского литературного языка. М.: Наука, 1970. С. 369-398.

Шапиро А.Б. Имя числительное // Грамматика русского языка. М.: Изд-во AH CCCP, 1953. T. 1. C. 368-386. 
Шмелев А.Д. Сколько форм словоизменения у слов типа сколько? 2005. [Электронный ресурc]. URL: https://inslav.ru/zalizniak80/congratulations/Shmelev.pdf (дата обращения: 23.07.2019).

Шмелев А. Д. Посессивы в русской грамматике // Динамические модели: Слово. Предложение. Текст. Сборник статей в честь Е. В. Падучевой. М., 2008. С. 927-942.

Шмелев А.Д. Супплетивизм или синонимия? // Смыслы, тексты и другие захватывающие сюжеты. Сборник статей в честь 80-летия И. А. Мельчука. М., 2012. C. 573-576.

Шмелев А.Д. Числительные и числовые конструкции в русском языке; лакуны в словарях и грамматических описаниях //Логический анализ языка: Числовой код в разных языках и культурах. М.: ЛЕНАНД, 2014. С. 57-67.

Bulygina T.V., Shmelev A.D. Quantifiers in the Dictionary // EURALEX'90: Proceedings of the IV International Congress. Malaga, 1990. P. 257-263.

Garde P. Grammaire russe. Paris: Institut d'études slaves, 1980. Vol. 1. 486 p.

\section{Alexey D. Shmelev}

Vinogradov Russian Language Institute of the Russian Academy of Sciences (Moscow, Russia)

shmelev.alexei@gmail.com

\section{INACCURATE GRAMMATICAL DESCRIPTIONS: CAN ONE CORRECT THEM?}

This paper studies various types of inaccuracies in the existing descriptions of the Russian grammar. These inaccuracies derive from different sources. In some cases, we deal with an oversight in the description, and a correction of the inaccuracy does not generate new linguistic knowledge. Such inaccuracies are of little interest. We deal with the contrary situation if the inaccuracy in the grammatical description stems from the fact that some phenomena have not come into the view of the grammarian. Here, one can correct the inaccuracy only if the linguist uncovers the phenomenon that other grammarians have overlooked. In other cases, we come up against the inconsistency between different parts of the description. Here, there may be various ways to make the description consistent, but in any case, we must abandon some of the contradictory statements. One should distinguish such cases from the cases when the description is not explicit enough, and one might make it technically correct (perhaps not the best one though) by means of special clarifications. It is important to keep in mind the consequences of such clarifications: every so often they result in an increasingly large and overly complex grammatical description (or some of its parts). Moreover, in some cases, an attempt to save the existing description by means of clarification causes the grammatical rules to be unnatural.

Keywords: grammatical description, grammatical rule, inaccurate descriptions, Russian language, pronouns, numerals, possessive adjectives, family names. 


\section{References}

Bulygina T.V., Shmelev A.D. [Natural linguistic mechanisms of quantification and parameters of quantitative assessment]. Referentsiya i problemy tekstoobrazovaniya [Reference and problems of text formation]. Moscow, 1988, pp. 5-18. (In Russ.)

Bulygina T. V., Shmelev A. D. Quantifiers in the Dictionary. EURALEX'90: Proceedings of the IV International Congress. Malaga, 1990, pp. 257-263.

Bulygina T.V., Shmelev A.D. [Semantic and morphological peculiarities of pronouns: the structure of paradigms]. Linguistique et slavistique. Mélanges offerts à Paul Garde [Linguistics and Slavic studies. Miscellanea to honor Paul Garde]. Paris, 1992, vol. 1, pp. 425-436. (In Russ.)

Bulygina T. V., Shmelev A.D. [Numerals in Russian]. Slovo v tekste i v slovare: Sb. st. $k$ 70-letiyu akad. Yu. D. Apresyana [Word in text and dictionary: a Festschrift to commemorate the $70^{\text {th }}$ anniversary of acad. Yu. D. Apresjan]. Moscow, 2000, pp. 289-306. (In Russ.)

Es'kova N. A., Borunova S. I., Vorontsova V.L. Orfoehpicheskii slovar' russkogo ya$z y k a$ [Orthoepic Dictionary of Russian]. Moscow, AST Publ., 2015. 1008 p. (In Russ.)

Garde P. Grammaire russe [Russian Grammar]. Paris, Institut d'études slaves, 1980, vol. 1. 486 p. (in French)

Kopchevskaya-Tamm M., Shmelev A. [Properties of the so-called Russian "possessive adjectives"]. Scando-Slavica, 1994, vol. 40, pp. 209-228. (In Russ.)

Plotnikova V.A. [Nominal inflection] Grammatika sovremennogo russkogo literaturnogo yazyka [Standard Modern Russian Grammar]. Moscow, 1970, pp. 369-398. (In Russ.)

Shapiro A.B. [Numeral]. Grammatika russkogo yazyka [Russian Grammar]. Moscow, 1953, vol. 1, pp. 368-386. (In Russ.)

Shmelev A.D. [Possessive Forms in Russian Grammar]. Dinamicheskie modeli: Slovo. Predlozhenie. Tekst. Sbornik statei v chest' E.V. Paduchevoi [Dynamic Models: Word. Sentence. Text. A Collection of Articles in Honor of E. V. Paducheva]. Moscow, 2008, p. 927-942. (In Russ.)

Shmelev A. D. [Suppletion or synonymy?]. Smysly, teksty i drugie zakhvatyvayushchie syuzhety. Sbornik statei $v$ chest' 80-letiya I.A. Mel'chuka [Meanings, Texts, and Other Exciting Things. A Festschrift to Commemorate the $80^{\text {th }}$ Anniversary of Professor Igor Alexandrovič Mel'čuk]. Moscow, 2012, pp. 573-576.

Shmelev A.D. [Numerals and numeral constructions in Russian: gaps in dictionaries and grammatical descriptions]. Logicheskii analiz yazyka: Chislovoi kod v raznykh yazykakh i kul'turakh [Logical Analysis of Language: Numeric Code in Various Languages and Cultures]. Moscow, 2014, p. 57-67. (In Russ.)

Shmelev A.D. Shmelev A.D. Skol'ko form slovoizmeneniya u slov tipa skol'ko? [Russian pronominal numerals: how many inflectional forms do they have?] 2005. Available at: https:/inslav.ru/zalizniak80/congratulations/Shmelev.pdf (accessed 23.07.2019). (In Russ.)

Zaliznyak A. A. Grammaticheskii slovar' russkogo yazyka. Slovoizmenenie [Grammatical Dictionary of Russian: Inflection]. Moscow, «Russkii Yazyk» Publ., 1977. 880 p. (In Russ.) 
Zaliznyak A.A. Grammaticheskii slovar' russkogo yazyka. Slovoizmenenie [Grammatical Dictionary of Russian: Inflection]. Moscow, «Russkie slovari» Publ., 2003. 800 p. (In Russ.)

Zaliznyak A.A. Grammaticheskii slovar' russkogo yazyka. Slovoizmenenie [Grammatical Dictionary of Russian: Inflection]. Moscow, «AST-PRESS KNIGA» Publ., 2008. 800 p. (In Russ.)

Научный журнал

ТРУДЫ ИНСТИТУТА РУССКОГО ЯЗЫКА ИМ. В.В. ВИНОГРАДОВА

№4. 2019

Грамматические процессы и системы в синхронии

Памяти Андрея Анатольевича Зализняка

Оригинал-макет Л.Е. Голод

Дизайн обложки И.А. Тимофеев

Подписано в печать 30.07.2020. Формат 70×100 ${ }^{1} / 16$

Бумага офсетная. Печать офсетная. Усл.-печ. л. 28. Заказ № 1984

Тираж 300 экз.

Адрес редакции: г. Москва, 119019, Волхонка 18/2

Издательство «Нестор-История»

197110 СПб., Петрозаводская ул., д. 7

Тел. (812)235-15-86

e-mail: nestor_historia@list.ru

www.nestorbook.ru

Отпечатано в типографии издательства «Нестор-История»

Тел. (812)235-15-86 